\title{
Relationship between TBX20 gene polymorphism and congenital heart disease
}

\author{
X.F. Yang ${ }^{1,2}$, Y.F. Zhang ${ }^{2}$, C.F. Zhao ${ }^{1}$, M.M. Liu ${ }^{1}$, J.P. Si ${ }^{3}$, Y.F. Fang ${ }^{2}$, \\ W.W. Xing ${ }^{2}$ and F.L. Wang ${ }^{2}$ \\ ${ }^{1}$ Department of Pediatrics, Qilu Hospital of Shandong University, Jinan, \\ Shandong, China \\ ${ }^{2}$ Department of Pediatrics, Yidu Central Hospital of Weifang City, Qingzhou, \\ Shandong, China \\ ${ }^{3}$ Department of Pediatrics, People's Hospital of GuangRao, Dongying, \\ Shandong, China \\ Corresponding author: C.F. Zhao \\ E-mail: cuifenzhao009@126.com
}

Genet. Mol. Res. 15 (2): gmr.15027374

Received August 5, 2015

Accepted December 14, 2015

Published June 3, 2016

DOI http://dx.doi.org/10.4238/gmr.15027374

\begin{abstract}
Congenital heart disease in children is a type of birth defect. Previous studies have suggested that the transcription factor, TBX20, is involved in the occurrence and development of congenital heart disease in children; however, the specific regulatory mechanisms are yet to be evaluated. Hence, this study aimed to evaluate the relationship between the TBX20 polymorphism and the occurrence and development of congenital heart disease. The TBX20 gene sequence was obtained from the NCBI database and the polymorphic locus candidate was predicted. Thereafter, the specific gene primers were designed for the restriction fragment length polymorphism-polymerase chain reaction (RFLP-PCR) of DNA extracted from the blood of 80 patients with congenital heart disease and 80 controls. The results of the PCR were subjected to correlation analysis to identify the differences between the amplicons and to determine the relationship between the TBX20 gene polymorphism and congenital heart disease. One of
\end{abstract}


the single nucleotide polymorphic locus was found to be rs3999950: c.774T $>$ C (Ala265Ala). The TC genotype frequency in the patients was higher than that in the controls, similar to that for the $\mathrm{C}$ locus. The odds ratio of the TC genotypes was above 1, indicating that the presence of the TC genotype increases the incidence of congenital heart diseases. Thus, rs3999950 may be associated with congenital heart disease, and TBX20 may predispose children to the defect.

Key words: TBX20 transcription factor; Gene polymorphism; Allele; Congenital heart disease; Single nucleotide polymorphism loci; Genotype frequency

\section{INTRODUCTION}

Congenital heart disease (CHD) is a type of birth defect with a relatively high incidence (Steeden et al., 2015), which ranges from about 4/1000 to 50/1000 (Webb et al., 2015). Each year approximately 200,000 to 250,000 children are born in China with this condition (Beltrão et al., 2015), endangering the lives and well-being of children as well as imposing enormous economic and emotional pressures on the families and society (Karpawich, 2015). Therefore, identifying the underlying molecular mechanism is essential for proper diagnosis and treatment and favorable prognosis of CHD (Zipkin et al., 2015).

Previous studies have shown that the occurrence and development of congenital birth defects in children were the result of multiple factors (Biglino et al., 2015). The major factors include environmental factors and genetic factors ( $\mathrm{Li}$ et al., 2016). While studies have shown that genetic factors constitute the main cause of congenital heart disease (Gaynor et al., 2015), environmental factors have not been emphasized enough in experiments (Amanullah et al., 2015). For a more accurate study of the role of genetic factors, birth conditions and the upbringing environment in both control and experiential groups should be the same (as was the case in this study) to erase the influence of environmental factors.

TBX20 belongs to the T-box gene family (Liu et al., 2008; Butler et al., 2010). Animal experiments have shown that TBX20 plays an important role in the normal development and function of the heart (Qiao et al., 2012) through interaction with target genes and regulation of gene transcription and translation processes (Töpf et al., 2014). An in vivo study has also indicated that by using RNAi technology, knock down of TBX20 or expression of TBX20 mutants causes mammalian heart disease (Chen et al., 2015). Furthermore, human studies have shown that missense mutations in the TBX20 gene is closely related to the occurrence of congenital heart disease in children (Monroy-Muñoz et al., 2015). However, the role of TBX20 in a Chinese population, especially children with congenital heart disease, needs to be clarified (Chen et al., 2015).

The evaluation of single nucleotide polymorphisms (SNP) is a key approach to explore and identify genetic predispositions to a certain condition (Lin et al., 2015), particularly for polygenic disease research (Kwiatkowski et al., 2015; Knopp et al., 2015). Through the study of SNPs in predisposing genes, the relationship between the gene and the disease can be clarified, which is of significant value for disease diagnosis, treatment, and prognosis. This study aims to identify the relationship between the TBX20 gene polymorphism and the occurrence and development of congenital heart disease. 


\section{MATERIAL AND METHODS}

\section{Patients}

Eighty children with congenital heart disease and 80 healthy children from the same family as the control group were selected for this study in accordance with the congenital heart disease selection criteria (Kin et al., 2011) and congenital heart disease exclusion criteria (Sendler et al., 2015) (from January 2010 to January 2015). The study was approved by the Qilu Hospital of Shandong University Ethics Committee. All the selected patients (or their guardians) signed the consent forms.

\section{TBX20 gene SNP prediction and analysis}

The United States National Center for Biotechnology Information (NCBI) database was used for TBX20 SNP prediction and analysis (Karpawich, 2015). The specific methods used were as follows: search key words in terms of "TBX20" and "Homo sapiens" were entered in the dbSNP database (BUILD138 version) from the NCBI website. A total of 942 SNPs related to human TBX20 were found. Human TBX20 had 17 SNPs.

\section{Collection of blood samples and genomic DNA extraction}

We extracted $5 \mathrm{~mL}$ venous blood from each patient using sodium citrate as the anticoagulant. The blood genomic DNA extraction kit was then used for the extraction of genomic DNA from each sample.

\section{PCR}

A pair of primers for the gene-specific sequence of the 5th exon of TBX20 was designed. The primer sequences were as follows: upstream primer 5'-CCTCACTGTAATTTGGCCTG-3' and downstream primer 5'-GCCCTGAAACTCAATAGCTC-3'. The primers were synthesized by Sanboyuanzhi Biotechnology Company (Beijing). The PCR mixture contained $2 \mu \mathrm{L}$ genomic DNA used as the template, $2.5 \mu \mathrm{L} 10 \mathrm{X}$ PCR buffer, $2.5 \mu \mathrm{L}$ each dNTP mixture (2 $\mathrm{mM}), 0.5 \mu \mathrm{L}$ primer $1(10 \mu \mathrm{M}), 0.5 \mu \mathrm{L}$ primer $2(10 \mu \mathrm{M}), 0.5 \mu \mathrm{L}$ Taq DNA Polymerase, 2.5 $\mu \mathrm{L} \mathrm{MgCl}_{2}(25 \mathrm{mM})$, and $14 \mu \mathrm{L} \mathrm{H}_{2} \mathrm{O}$. The PCR conditions were as follows: $94^{\circ} \mathrm{C}$ for $7 \mathrm{~min}$, $94^{\circ} \mathrm{C}$ for $30 \mathrm{~s}, 50^{\circ} \mathrm{C}$ for $60 \mathrm{~s}$ for 28 cycles, followed by $72^{\circ} \mathrm{C}$ for $30 \mathrm{~s}, 72^{\circ} \mathrm{C}$ for $5 \mathrm{~min}$, and $4^{\circ} \mathrm{C}$ for thermal insulation.

\section{Agarose gel detection for the PCR product}

The PCR product was then visualized on $1 \%$ agarose gel. The PCR product $(10 \mu \mathrm{L})$ and $2 \mu \mathrm{L} 6 \mathrm{X}$ sample buffer were added into the agarose gel and electrophoresed at $50 \mathrm{mV}$ for $20 \mathrm{~min}$. After completion of the electrophoresis process, pictures were taken using the gel imaging system and saved. Thus, the PCR results were preliminarily detected. 


\section{Sequences of PCR products}

The PCR products were then sent to Sanboyuanzhi Biotechnology Company for sequencing. The sequencing results were compared and analyzed to further validate the PCR amplification products and the TBX20 genome sequence.

\section{Statistical analysis}

The SPSS 16.0 software was used to analyze the data. Data are reported as means \pm standard deviation (means $\pm \mathrm{SD}$ ). Comparisons between the groups were performed using singlefactor analysis of variance (one-way ANOVA). $\mathrm{P}<0.05$ was considered statistically significant.

\section{RESULTS}

\section{Basic information regarding the study subjects}

From January 2010 to January 2015, 80 children with CHD and 80 healthy children from the same family (as the control group) were enrolled in this study.

The cases of the 80 children with CHD were in accordance with the CHD selection criteria and other types of congenital malformations were excluded. In total, 48 cases of septal defect types (including ventricular septal defects and atrial septal defects), 8 cases with tetralogy of Fallot, 6 cases of patent ductus arteriosus with ventricular septal defect, 5 cases of transposition with ventricular septal defect, 6 cases of closure of patent ductus arteriosus, and 7 cases of atrial septal defect and ventricular septal defect with patent ductus arteriosus were identified. Patients had an average age of $12.85 \pm 6.16$ years and the gender ratio was 1:1.

The control group consisted of 80 healthy children with an average age of $12.18 \pm$ 6.82 years, and the gender ratio was 1:1 (Table 1 ).

\section{Table 1. Comparison of basic information between experimental and control groups.}

\begin{tabular}{l|c|c|c|c|c|c|c}
\hline Group types & $\mathrm{N}$ & Age & Gender & $\begin{array}{c}\text { No. of septal defect } \\
\text { cases }\end{array}$ & $\begin{array}{c}\text { No. of tetralogy of } \\
\text { Fallot cases }\end{array}$ & $\begin{array}{c}\text { No. of patent ductus } \\
\text { arteriosus associated } \\
\text { with ventricular septal } \\
\text { defect cases }\end{array}$ & $\begin{array}{c}\text { No. of special } \\
\text { cases }\end{array}$ \\
\hline CHD group & 80 & $12.85 \pm 6.16$ & $40 / 40$ & 48 & 8 & 6 & 0 \\
\hline Control group & 80 & $12.18 \pm 6.82$ & $40 / 40$ & 0 & 0 & 0 & 0.0012 \\
\hline P values & & 0.10 & 0.5 & 0.0043 & & 0.0001 \\
\hline
\end{tabular}

\section{Agarose gel electrophoresis of the PCR products}

The 260/280 value was around 1.8 in each group when blood genomic DNA concentration was $226-360 \mathrm{ng} / \mu \mathrm{L}$, which indicated that the quality of the extracted genomic DNA was good and that it can be used for PCR amplification.

Results of the agarose gel electrophoresis of the PCR product of the 5th exon of $T B X 20$ is shown in Figure 1; the product size was $350 \mathrm{bp}$, which is the same as that of $T B X 20$ genes corresponding to the designed primers. No non-specific bands were observed.

$T B X 20$ gene fragments obtained following restriction enzymatic digestion by EcoRI and $X b a \mathrm{I}$ are shown in Figure 2; these were consistent with the theoretical predictions. 


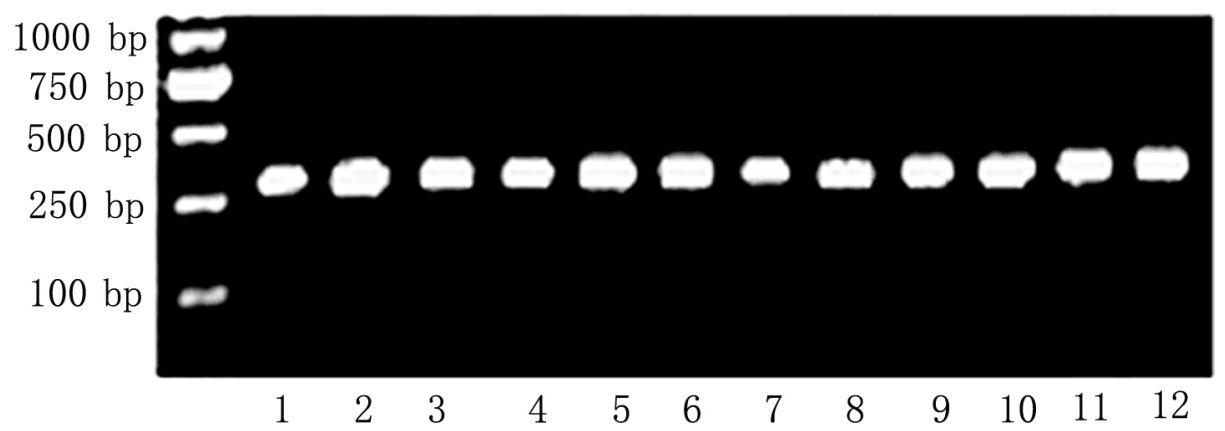

Figure 1. Results of agarose gel detection for the polymerase chain reaction products. Lanes 1-6 show the PCR products from genomic DNA isolated from blood samples of congenital heart disease patients; lanes 7-12 show the PCR products from genomic DNA isolated from blood samples of controls.

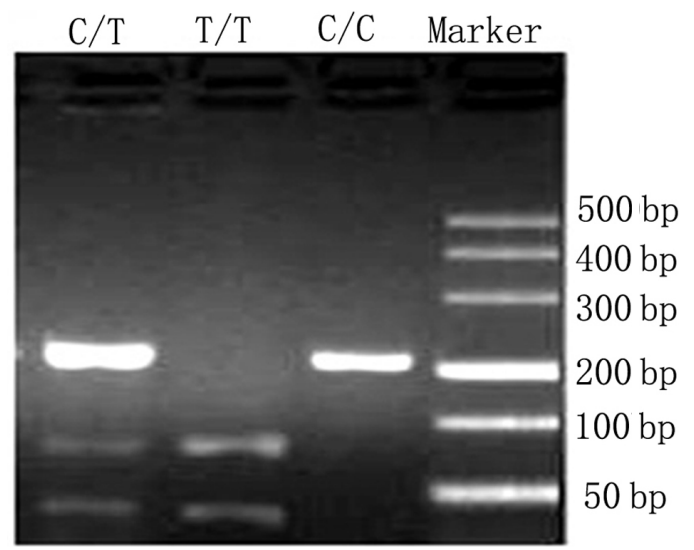

Figure 2. Results of enzymatic digestion of the $T B X 20$ gene.

\section{PCR product sequencing results}

Sequencing results obtained after a forward and reverse sequencing of DNA samples from the 160 study subjects are shown in Figure 3; the success rate of sequencing was above 99\%.

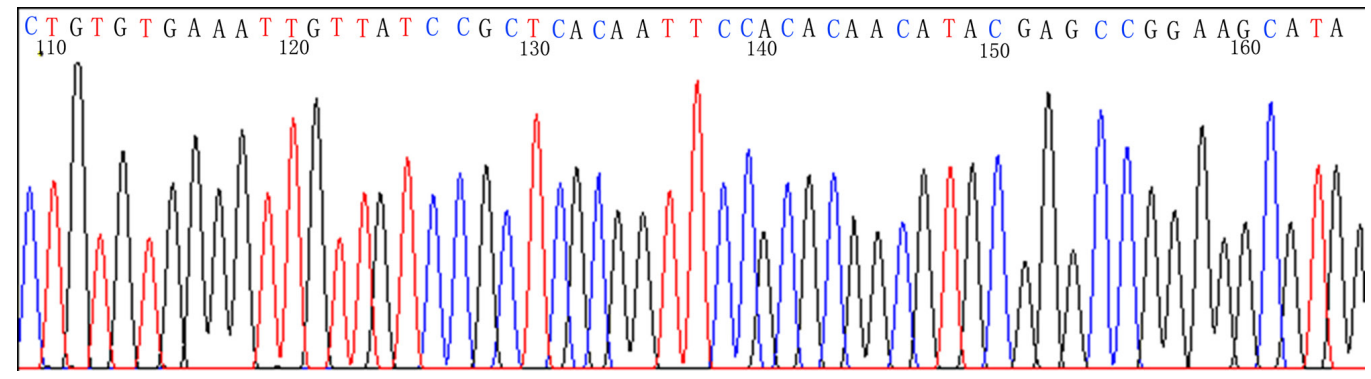

Figure 3. Sequencing results of the PCR products. 


\section{Comparison of sequencing results}

Sequencing results were compared with sequences of the TBX20 gene obtained from the NCBI database; the corresponding results are shown in Figure 4. Sequencing results of the PCR products of the TBX20 gene and the sequence of TBX20 obtained from NCBI were identical, with sequence homology reaching $98 \%$.

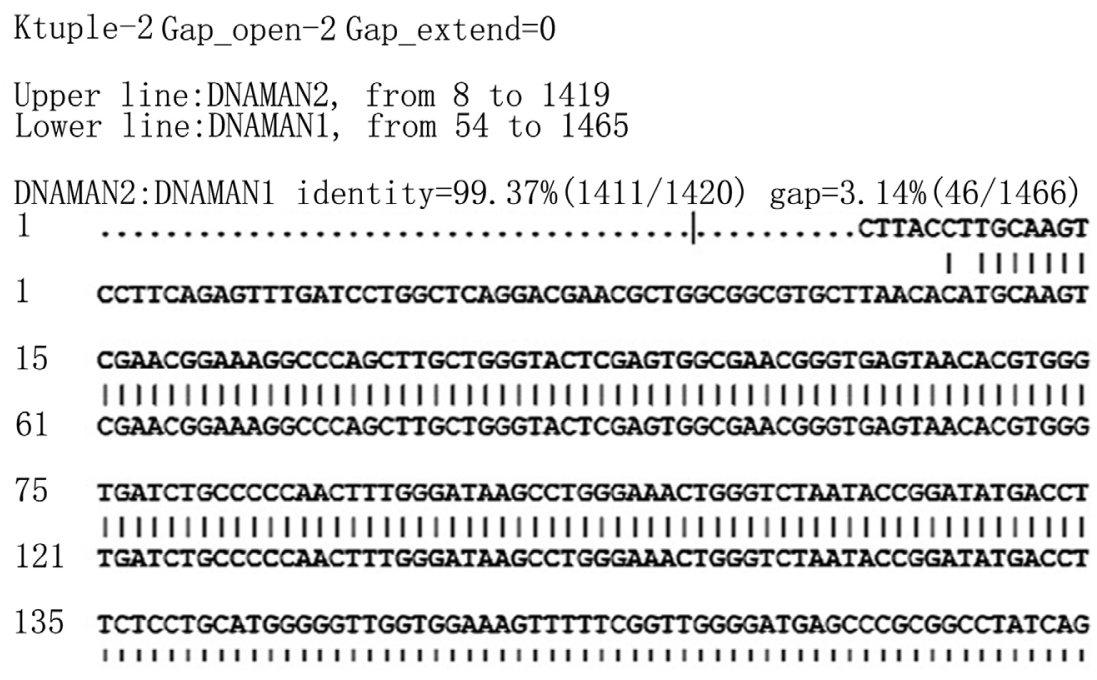

Figure 4. Results of the inter-group comparisons performed for the sequencing results.

\section{Results of SNP analysis of the TBX20 gene}

PCR products of the TBX20 gene were genotyped and subjected to Hardy-Weinberg genetic equilibrium test to evaluate population representativeness. Results show that the distribution of the TBX20 SNP among the study subjects was in accordance with HardyWeinberg genetic equilibrium. Sequencing results have shown that the $T B X 20$ gene existed as a single nucleotide polymorphism locus, rs3999950: c.774T $>$ C(Ala265Ala), as shown in Figure 5.

\section{SNP allele frequency and genotype frequency of the TBX20 gene}

PCR products were subjected to Hardy-Weinberg genetic equilibrium test to evaluate population representativeness. The distribution of the TBX20 SNP among the study subjects was in accordance with Hardy-Weinberg genetic equilibrium (as shown in Figures 2 and 3). SNP allele frequency and genotype frequency of the TBX20 gene were compared in both the CHD patient group and the healthy control group. The TC genotype frequency of the rs3888850 locus in the patient group is higher than that in the control group, similar to that observed for the $\mathrm{C}$ locus. There are significant differences between patients and the control group. OR of the TC genotype was above 1; thus, the TC genotype is associated with an increased incidence of CHD. 


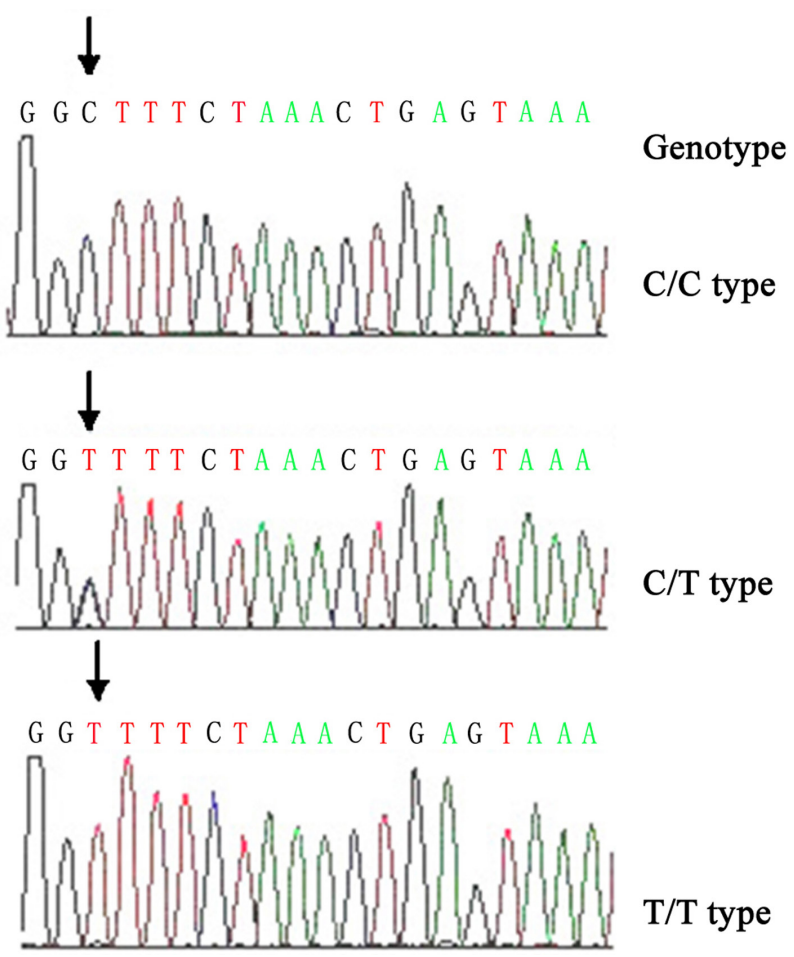

Figure 5. SNP analysis of $T B X 20$. Arrows in the figure indicate the $T B X 20$ polymorphism loci.

\section{DISCUSSION}

Our study has two main points of novelty. First, we discovered a new single nucleotide polymorphic locus on TBX20, rs3999950: c.774T $>$ C (Ala265Ala). Second, the TBX20 transcription factor gene polymorphism - rs3999950 - is closely associated with congenital heart disease. Therefore, polymorphism in TBX20 can be considered a new genetic predisposition for CHD.

CHD has seriously threatened the lives and wellbeing of numerous children (Welliver et al., 2010); therefore, there are significant meanings to study it. Previous studies have shown that TBX20 polymorphisms are closely related to the occurrence and development of CHD in children (Chen et al., 2015; Kwiatkowski et al., 2015; Lin et al., 2015; Monroy-Muñoz et al., 2015), results of this study were in concordance with those of previous studies. TBX20 SNP loci that have been reported thus far include: rs6950175 and rs3999941. Through a strictly controlled and double-blinded trial, we found that the TBX20 polymorphism, rs3999950, was closely related to CHD in children. Experimental data from this study evidence the possibility of the TBX20 polymorphism, rs3999950, being a genetic predisposition for CHD in children. First, the TC genotype frequency of the rs 3888850 loci was higher in the experienced group than in the control group; second, the frequency of the $\mathrm{C}$ loci was the same as the rs3888850 loci; third, OR of the TC genotypes were above 1, i.e., the TC genotype increases the incidence of CHD.

However, there were 3 major limitations in this study. First, the number of cases might be considered low as only 80 cases of CHD were considered for this study. Therefore, 
further studies should include a larger cohort and more random objects, multi-center doubleblind studies should be conducted to explore the relationship between the polymorphisms in the rs3999950 locus of TBX20 and CHD (Yan et al., 2011); second, owing to the small cohort size, we did not compare different types of CHD, such septal defect types including ventricular septal defect, atrial septal defect, tetralogy of Fallot, patent ductus arteriosus with ventricular septal defect, transposition with ventricular septal defect, closure of patent ductus arteriosus, ventricular septal defect with atrial septal defect, and closure of patent ductus arteriosus. This would further provide information in terms of the relationship between TBX20 polymorphisms and the occurrence and development of CHD. Third, patients were not further classified according to their age, gender, and ethnicity.

To summarize, our results demonstrated that a TBX20 polymorphism, rs3999950, is closely associated with CHD. Nevertheless, further research is warranted.

\section{Conflicts of interest}

The authors declare no conflict of interest.

\section{ACKNOWLEDGMENTS}

We thank the anonymous reviewers for reviewing this manuscript.

\section{REFERENCES}

Amanullah MM, Hamid M, Hanif HM, Muzaffar M, et al. (2015). Effect of steroids on inflammatory markers and clinical parameters in congenital open heart surgery: a randomised controlled trial. Cardiol. Young 28: 1-10. http://dx.doi. org/10.1017/S1047951115000566

Beltrão BA, Herdman TH, Pascoal LM, Chaves DB, et al. (2015). Ineffective breathing pattern in children and adolescents with congenital heart disease: accuracy of defining characteristics. J. Clin. Nurs. 24: 2505-2513. http://dx.doi. org/10.1111/jocn. 12838

Biglino G, Capelli C, Wray J, Schievano S, et al. (2015). 3D-manufactured patient-specific models of congenital heart defects for communication in clinical practice: feasibility and acceptability. BMJ Open 5: e007165.http://dx.doi. org/10.1136/bmjopen-2014-007165

Butler TL, Esposito G, Blue GM, Cole AD, et al. (2010). GATA4 mutations in 357 unrelated patients with congenital heart malformation. Genet. Test. Mol. Biomarkers 14: 797-802.http://dx.doi.org/10.1089/gtmb.2010.0028

Chen J, Sun F, Fu J and Zhang H (2015). Association of TBX20 gene polymorphism with congenital heart disease in Han Chinese neonates. Pediatr. Cardiol. 36: 737-742.http://dx.doi.org/10.1007/s00246-014-1073-5

Gaynor JW, Stopp C, Wypij D, Andropoulos DB, et al.; International Cardiac Collaborative on Neurodevelopment (ICCON) Investigators (2015). Neurodevelopmental outcomes after cardiac surgery in infancy. Pediatrics 135: 816825.http://dx.doi.org/10.1542/peds.2014-3825

Karpawich PP (2015). Improving pacemaker therapy in congenital heart disease: contractility and resynchronization. Semin. Thorac. Cardiovasc. Surg. Pediatr. Card. Surg. Annu. 18: 51-56.http://dx.doi.org/10.1053/j.pcsu.2014.12.002

Kin N, Weismann C, Srivastava S, Chakravarti S, et al. (2011). Factors affecting the decision to defer endotracheal extubation after surgery for congenital heart disease: a prospective observational study. Anesth. Analg. 113: 329-335. http://dx.doi.org/10.1213/ANE.0b013e31821cd236

Knopp C, Rudnik-Schöneborn S, Eggermann T, Bergmann C, et al. (2015). Syndromic ciliopathies: From single gene to multi gene analysis by SNP arrays and next generation sequencing. Mol. Cell Probes pii: S0890-8508: 30005-30000.

Kwiatkowski D, Czarny P, Galecki P, Bachurska A, et al. (2015). Variants of base excision repair genes MUTYH, PARP1 and XRCC1 in Alzheimer's disease risk. Neuropsychobiology 71: 176-186. http://dx.doi.org/10.1159/000381985

Li X, Sundquist J, Hamano T, Zöller B, et al. (2016). Neighbourhood, deprivation, individual-level and familial-level socio-demographic factors and risk of congenital heart disease: a nationwide study from Sweden. Int. J. Behav. Med. 23: $112-120$. 
TBX20 gene polymorphism and congenital heart disease

Lin SB, Xie YJ, Chen Z, Zhou Y, et al. (2015). Improved assay performance of single nucleotide polymorphism array over conventional karyotyping in analyzing products of conception. J. Chin. Med. Assoc. 78: 408-413. http://dx.doi. org/10.1016/j.jcma.2015.03.010

Liu C, Shen A, Li X, Jiao W, et al. (2008). T-box transcription factor TBX20 mutations in Chinese patients with congenital heart disease. Eur. J. Med. Genet. 51: 580-587.http://dx.doi.org/10.1016/j.ejmg.2008.09.001

Monroy-Muñoz IE, Pérez-Hernández N, Rodríguez-Pérez JM, Muñoz-Medina JE, et al. (2015). Novel mutations in the transcriptional activator domain of the human TBX20 in patients with atrial septal defect. BioMed Res. Int. 2015: 718786. http://dx.doi.org/10.1155/2015/718786

Qiao Y, Wanyan H, Xing Q, Xie W, et al. (2012). Genetic analysis of the TBX20 gene promoter region in patients with ventricular septal defects. Gene 500: 28-31.http://dx.doi.org/10.1016/j.gene.2012.03.055

Sendler M, Beyer G, Mahajan UM, Kauschke V, et al. (2015). Complement component 5 mediates development of fibrosis, via activation of stellate cells, in 2 mouse models of chronic pancreatitis. Gastroenterology 149: 765-76.e10. http://dx.doi.org/10.1053/j.gastro.2015.05.012

Steeden JA, Pandya B, Tann O and Muthurangu V (2015). Free breathing contrast-enhanced time-resolved magnetic resonance angiography in pediatric and adult congenital heart disease. J. Cardiovasc. Magn. Reson. 17: 38. http:// dx.doi.org/10.1186/s12968-015-0138-9

Töpf A, Griffin HR, Glen E, Soemedi R, et al. (2014). Functionally significant, rare transcription factor variants in tetralogy of Fallot. PLoS One 9: e95453. http://dx.doi.org/10.1371/journal.pone.0095453

Webb RH, Gentles TL, Stirling JW, Lee M, et al. (2015). Valvular regurgitation using portable echocardiography in a healthy student population: implications for rheumatic heart disease screening. J. Am. Soc. Echocardiogr. 28: 981988. http://dx.doi.org/10.1016/j.echo.2015.03.012

Welliver RC, Sr., Checchia PA, Bauman JH, Fernandes AW, et al. (2010). Fatality rates in published reports of RSV hospitalizations among high-risk and otherwise healthy children. Curr. Med. Res. Opin. 26: 2175-2181. http://dx.doi. org/10.1185/03007995.2010.505126

Yan H, Tang M, You Y, Yu JB, et al. (2011). Treatment of psoriasis with recombinant human LFA3-antibody fusion protein: a multi-center, randomized, double-blind trial in a Chinese population. Eur. J. Dermatol. 21: 737-743.

Zipkin R, Ostrom K, Olowoyeye A, Markovitz B, et al. (2015). Association Between Implementation of a Cardiovascular Step-Down Unit and Process-of-Care Outcomes in Patients With Congenital Heart Disease. Hosp. Pediatr. 5: 256262. http://dx.doi.org/10.1542/hpeds.2014-0046 